\title{
¿Qué ha pasado con la cooperación internacional para la participación de las OSC colombianas? ${ }^{12}$
}

\author{
What has happened to international cooperation \\ for the participation of Colombian CSOs?
}

\section{Erli Margarita Marín-Aranguren ${ }^{3}$}

Resumen: En este artículo se recoge un trabajo de investigación que busca alejarse de la tradicional mezcla de ayuda oficial al desarrollo (AOD) y Cooperación Internacional $(\mathrm{Cl})$, para mostrar el comportamiento de los donantes/oferentes para el robustecimiento de la democracia, vía el fortalecimiento de las organizaciones de la sociedad civil (OSC). Esto con el fin de encontrar: ¿qué ha pasado con la cooperación internacional para la participación de las organizaciones de la sociedad civil colombiana? La realidad es que, si bien hay apuestas para su fortalecimiento, es poco lo que se conoce. Esta investigación encuentra que las OSC contribuyen al establecimiento de un diálogo público, al refuerzo de la veeduría, el control social y la participación política. Del lado de los cooperantes, se encontró que las agencias de cooperación internacional son generadoras de un entorno habilitante favorable para las OSC. De hecho, descubren nuevos roles para ellas.

Palabras clave: Sociedad civil, cooperación al desarrollo, ambiente habilitante o entorno propicio, oferta de valor y participación.

Abstract: This article includes a line if research that seeks to move away from the traditional mix of official development assistance (ODA) and International Cooperation (IC), in order to show the behaviour of donors/suppliers working towards the consolidation of democracy by strengthening civil society organizations (CSO). The purpose is to find out what has happened to international cooperation for the participation of Colombian civil society organizations. In reality, while there have been attempts at strengthening them, little is still known. This research concludes that CSOs contribute to the establishment of public dialogue, social control and political participation. In connection with aid providers, it has been found out that international cooperation agencies create an enabling environment favourable to CSOs and, in fact, discover new roles for these organizations.

Key words: Civil society, development cooperation, enabling environment, value and participation offer.

\footnotetext{
${ }^{1}$ Recibido: 02/05/2018. Aceptado: 08/10/2018

${ }^{2}$ Este artículo se basa en la ponencia presentada en el V Congreso de la Red Colombiana de Relaciones Internacionales (Redintercol) que fue presentada el 13 de octubre de 2017, evento que tuvo lugar en la sede de la Universidad del Rosario en Bogotá.

${ }^{3}$ Investigadora y profesora titular Centro de Investigaciones y Proyectos Especiales (Cipe) Facultad de Finanzas, Gobierno y Relaciones Internacionales Universidad Externado de Colombia.Correo electrónico: erli.marin@uexternado.edu.co
} 


\section{Introducción}

Cuando se considera la Cooperación Internacional $(\mathrm{Cl})$ se tiende a pensar en donantes y receptores. Bueno, los que hacen una aproximación tradicional. Los avezados en la nueva arquitectura de la cooperación, corregirán y harán referencia a: los donantes, los socios, los principios ${ }^{4}$ y los temas. Luego del primer quindenio del siglo XXI, sin duda, muchos más tratan de establecer cómo este instrumento posibilita el éxito geoestratégico en términos democráticos. Por eso, para esta investigación me he alejado de la tradicional mezcla de ayuda oficial al desarrollo (AOD) y $\mathrm{Cl}$ para mostrar el comportamiento de los donantes /oferentes para el robustecimiento de la democracia, vía el fortalecimiento de las organizaciones de la sociedad civil (OSC) y su participación en la gestión de política pública. Por eso, la pregunta que dio origen a esta investigación fue ¿qué ha pasado con la cooperación internacional para la participación de las organizaciones de la sociedad civil colombiana? La realidad es que, si bien hay una larga tradición de apuestas para su fortalecimiento, es poco lo que se conoce. Algunas veces, cuando se analiza la cooperación, las referencias se centran en los montos. Muchas veces, el eje es el cooperante: Unión Europea, Estados Unidos, Canadá, China, y así.

De una u otra manera, lo que es claro es que el contexto colombiano de posacuer$\mathrm{do}^{5}$, ha sido posible gracias a la voluntad política y también a la participación de las organizaciones de la sociedad civil. El respaldo de la $\mathrm{Cl}$ a las OSC colombianas ha sido fundamental para el trabajo de incidencia/advocacy en la construcción de la agenda internacional (medio ambiente, ODS, drogas, derechos humanos, entre otros)

En este artículo se quiere recoger los resultados de una investigación que mostró que la cooperación internacional jugó un papel estratégico para llegar a este punto, pero aún se requiere consolidar el ambiente habilitante que se ve amenazado con restricciones normativas y con el asesinato de líderes sociales. El mayor énfasis de la investigación estuvo en la construcción del acuerdo de paz, proceso que tiene un hito con la firma, pero que ha de continuar para alcanzarla. Los analistas de esos asuntos (violentólogos y otros analistas del conflicto colombiano) han advertido que, en los próximos años, se viene un periodo que no es precisamente de tranquilidad. Ya lo vemos con los asesinatos de líderes sociales: más de 311 casos registrados ${ }^{6}$ (Defensoría del Pueblo, 2018) En el Acuerdo Final, el del 24 de noviembre de 2016, la participación de las organizaciones de

\footnotetext{
${ }^{4}$ En la Declaración de París sobre la Eficacia de la Ayuda (2005) se establecieron: apropiación, alineación, armonización, gestión orientada a resultados y, responsabilidad mutua.

${ }^{5}$ Luego de la firma del Acuerdo final para la terminación del conflicto y la construcción de una paz estable y duradera, en Colombia empieza a hacerse referencia del posacuerdo, antes que del posconflicto toda vez que los violentólogos y analistas del conflicto armado han advertido sobre el incremento de la violencia en los años subsiguientes. Hay también quienes consideran que lo mejor es hacer referencia al periodo de transición.

${ }^{6}$ Los registros entre el 1 de enero de 2016 y 5 de julio de 2017 alcanzaron los 180 líderes asesinados. Ampliar en http://caracol.com.co/radio/2017/07/13/nacional/1499969113 783056.html Por esto, la $\mathrm{ONU}$, en su informe sobre derechos humanos, hace un llamado sobre la situación de líderes y lideresas y, alerta sobre los impactos que ello ocasiona para la consolidación de la paz. Ampliar en http://www.semana.com/nacion/articulo/onu-preocupada-por-asesinato-de-lideres-sociales/518741. En el informe de julio de 2018 la cifra se había incrementado a 311 entre 01 de enero de 2016 y 30 de junio de 2018, recuérdese que el horizonte de la investigación es hasta junio de 2017.
} 
la sociedad civil es necesaria no sólo para la implementación de lo acordado en La Habana sino para favorecer la democracia participativa que se requiere para Colombia en el corto, mediano y largo plazo.

En razón a ello, cuando se consideró este proyecto de investigación, se estableció como eje orientador el apoyo que -con cooperación internacional- han logrado las organizaciones de la sociedad civil para contar con entornos habilitantes que les den juego social y político. Ellas, las OSC colombianas, no solo son agentes en la arena local, nacional y global, sino que interactúan con la institucionalidad ${ }^{7}$, según el contexto geográfico y temporal. Y como agentes, son las llamadas a robustecer la democracia participativa ${ }^{8}$. Solo se hacen algunas referencias globales de sus incidencias, para centrar la atención en el ámbito interno.

Para valorar la información, en términos de poder encontrar una respuesta a la pregunta planteada (¿qué ha pasado con la cooperación internacional para la participación de las organizaciones de la sociedad civil colombiana?), se estableció como horizonte temporal, los años corridos del presente siglo hasta el 15 de junio de 2017. La metodología utilizada fue retrospectiva, expositiva y cualitativa. Para la obtención de datos se trabajó con fuentes secundarias, para conocer de la actividad de las organizaciones y reforzar conceptos teóricos, mediante la literatura académica. Se allegó información de fuentes primarias, tanto desde la perspectiva de los cooperantes como de los socios. Para ello se aplicaron entrevistas semiestructuradas tanto en agencias de cooperación (Unión Europea, Agencia Suiza, Embajada de Francia e incluso la Agencia Presidencial de Cooperación Internacional) ${ }^{9}$, como en OSC nacionales (Corporación Nuevo Arco Iris, Fundación Paz y Reconciliación, Cinep y la propia Confederación Colombiana de ONG) ${ }^{10}$, que han recibido recursos de $\mathrm{Cl}$. Luego, se cruzó la información encontrada, de suerte que la valoración de los hallazgos permitiera esbozar consideraciones finales, a manera de conclusión, en términos del robustecimiento de las OSC, para la participación política, con el apoyo de la cooperación internacional.

De manera que, aquí se comenzará por plantear unos lineamientos conceptuales básicos. Luego, se expondrán los hallazgos iniciales de la investigación, recogidos tanto en la investigación de segundas fuentes como en las entrevistas realizadas. Y finalmente, se plantearán algunas consideraciones, a manera de conclusión.

\footnotetext{
${ }^{7}$ Las instituciones, para Douglas North (1993: 13), son "las reglas de juego en una sociedad o expresado más formalmente, las instituciones serían las limitaciones ideadas por las personas que dan forma a la interacción humana". Es decir, reglas de juego formales (sistema de leyes) e informales (sistema de creencias y valores) para limitar las interacciones políticas, económicas y sociales. Ampliar en http://ebour.com.ar/pdfs/Instituciones,\%20de\%20Douglass\%20North.pdf

${ }^{8}$ Esfera pública, toma de decisiones, ejecución de decisiones, control de la ejecución, entre otras formas de participación.

${ }^{9}$ Dado que se trata de un trabajo exploratorio se tomaron aleatoriamente las agencias que rápidamente dieron respuesta a la solicitud de la entrevista.

${ }^{10}$ Dado que se trata de un trabajo exploratorio, se solicitó entrevista en varias organizaciones y se tomó la información de las que primero dieron respuesta positiva para la facilitación de la información. Aquí solo se nombra a las que dieron respuesta y se omiten las demás.
} 


\section{De los conceptos clave}

Para el abordaje de la investigación fue necesario precisar cinco conceptos clave: Sociedad civil, cooperación al desarrollo, ambiente habilitante o entorno propicio, oferta de valor y participación (de manera precisa, participación política)

Dado el carácter polisémico del término sociedad civil, ha de aclararse que más que ser un problema, como algunos autores lo denotan (Massal, 2007) (Ianni, 2005), lo que se percibe es una gran riqueza enmarcada en su heterogeneidad:

Pléyade de organizaciones ciudadanas de diversa índole, como son las asociaciones, las fundaciones, las empresas sin fines de lucro, las compañías de beneficio público y de beneficio mutuo, los clubes deportivos, los grupos de promoción y defensa de diversos derechos, las organizaciones culturales y artísticas, los sindicatos y asociaciones profesionales, las organizaciones de ayuda humanitaria, los proveedores de servicios sin fines de lucro, los fideicomisos de beneficencia y los partidos políticos (Acosta, 2013, p.149)

En este artículo, se comparte esta definición nominativa de lo que son las organizaciones de la sociedad civil, y a las cuales se hará referencia más que como espacio público -que lo es- por la capacidad instrumental para generar interacción y, para fundar lo solidario. Para construir democracia, porque canaliza demandas, cuenta con estrategias de movilización, visibiliza problemas y presenta propuestas técnicas (Diez de Sollano, 2015, p.145-165)

Con ello claro, vale la pena recordar los cuatro criterios que señalan Glennie y Alonso (2015), luego de insistir que la cooperación al desarrollo no es solo ayuda oficial al desarrollo, financiación al desarrollo, financiación pública internacional, ni total apoyo oficial al desarrollo. Hay que tener presente que ésta -explícitamente- apoya las prioridades de desarrollo nacionales o internacionales; no está impulsada por los beneficios; está orientada a favor de los países en vía de desarrollo y, se basa en relaciones de cooperación que buscan mejorar las capacidades de los países en desarrollo. De esta manera, se insiste en que el eje de la cooperación es la manera como dos actores/agentes deciden operar para corregir una situación que ha sido percibida como problemática en el contexto interno, para el caso de esta investigación. Se va más allá de solo considerar a los actores estatales, y se da paso a todas las OSC que estén involucradas.

Ahora bien, si nos quedamos con el enfoque de la gobernanza global que propone el profesor Tassara (2016, p.105), como el camino o ruta de la cooperación, para los próximos años, se precisa observar el entorno propicio ${ }^{11}$ existente internacional y localmente para las OSC.

De un lado se encuentra que, en el seno del Programa de las Naciones Unidas para el Desarrollo (PNUD) (s.f.) se han establecido tres objetivos para fortalecer a las OSC:

- En primer lugar, invertir en la sociedad civil y la participación ciudadana, facilitando un entorno propicio, apoyo y colaboración y revitalizando la capacidad del PNUD para trabajar con una gama más amplia de actores de la sociedad civil.

\footnotetext{
${ }^{11}$ También conocido como ambiente habilitante, hace referencia al "contexto en el cual las organizaciones ejercen su(s) rol(es), reconociendo las potencialidades y obstáculos en materia legal, política, institucional, financiera, de seguridad, técnica y de articulación entre ellas y otros actores sociales" (CCONG, 2014).
} 
- En segundo lugar, promover la acción ciudadana hacia el desarrollo y una democracia participativa, mediante el apoyo a la acción colectiva ciudadana.

- En tercer lugar, involucrar activamente a una amplia gama de actores no estatales, para un multilateralismo exterior que refuerce la participación ciudadana y el desarrollo humano.

De otro lado, en todo el mundo, las OSC enfrentan amenazas importantes (Acosta, 2013) que van de la represión política, la limitación jurídica, la obstaculización del encuentro y hasta de la posibilidad de acceder a recursos económicos que le posibiliten sostenibilidad e incluso se desalienta la actividad con la incapacidad de proteger a las personas y/o activistas. En aras de vencer estos desafíos que enfrentan las organizaciones, en 2011, en la Organización de Estados Americanos (OEA) se adoptó una resolución sobre la promoción de los derechos de libertad de reunión y asociación de las américas y, se creó un Grupo de Trabajo para fortalecer y Proteger a la Sociedad Civil en el seno de la Comunidad de Democracias ${ }^{12}$ (NED y ICNL, s.f.)

No se olvide que la política de asociación estratégica entre la Unión Europea y los países de América Latina y el Caribe tiene tres pilares para la acción exterior: diálogo político, la cooperación para el desarrollo y el comercio. De manera que, cuando se prepara la hoja de ruta para las actuaciones en Colombia (Unión Europea, s.f: 2), como aquí es el caso, las directrices señalan: la promoción de un entorno favorable a las OSC en los países socios, la participación significativa y estructurada en las políticas nacionales y, aumentar la capacidad de las OSC; es decir, no sólo visibilizar su oferta de valor sino cualificarla.

En estos términos, indudablemente, debe hacerse directa referencia a la oferta de valor. Un concepto que si bien está en construcción ya empieza a lograr apropiación en las mismas OSC. Básicamente, la oferta de valor, para la Confederación Colombiana de ONG (CCONG, 2016), puede ser definida como aquellas fortalezas que les permiten a las OSC potencializarse como agentes de desarrollo. Hoy se sabe que demostrar esta oferta de valor puede contribuir con su propia sostenibilidad en el tiempo. Vistas desde la perspectiva de agentes de desarrollo, las OSC contribuyen al establecimiento de un diálogo público que incide en el ciclo de las políticas públicas. En otras palabras, sus capacidades y habilidades técnicas y legales, su legitimidad moral y ética y, las metodologías y alternativas que desarrollan, les dan un aval que se convierte en su sello diferenciador.

De hecho, es esa oferta de valor la que les permite mejorar las oportunidades y ejercer influencia en el proceso de toma de decisiones. Les posibilita participar en el sistema político. Por eso, aquí se precisa la conceptualización de Pasquino (1993, p.181) cuando anota que "se puede hablar de política como actividad en comunidades organizadas (...) [que] está estrechamente relacionada, en su sentido fuerte, a significativos cambios socio-económicos y de la naturaleza de las comunidades políticas". En realidad, la participación política tiene abundantes definiciones, por eso -para los efectos de este artículo- se tomará la que anota que:

Es aquel conjunto de actos y actitudes dirigidos a influir de manera más o menos directa y más o menos legal sobre las decisiones de los detentadores del poder en el sistema político o en cada una de las organizaciones políticas, así como en su misma

\footnotetext{
${ }^{12}$ Coalición Intergubernamental global de países democráticos.
} 
selección, con vistas a conservar o modificar la estructura (y por lo tanto los valores) del sistema de intereses dominante (Pasquino, 1993, p. 180)

En concreto, cuando se quiere advertir ¿qué ha pasado con la cooperación internacional para la participación de las organizaciones de la sociedad civil en Colombia? Se deben entrelazar estos cinco términos.

\section{Una retrospectiva para hacer prospectiva}

Si bien la retrospectiva se limita a este siglo, el recorrido abarca: dos años de la administración de Andrés Pastrana Arango (1998-2002); ocho años de gobierno de Álvaro Uribe Vélez (2002-2010) y administración y media de Juan Manuel Santos Calderón (2010- junio 2017) No se trata de examinar estas administraciones presidenciales, pero sí de observar el comportamiento de la cooperación internacional en la que se conoce como "la democracia más antigua de América Latina"13. Y no precisamente por la participación electoral, toda vez que se sabe que ésta no agota -de ninguna manera- la actividad de la participación política (Pasquino, 1993, p.189) Pero, sí haciendo énfasis en que "las organizaciones constituyen el instrumento principal" (Pasquino, 1993, p.187), en tanto que -como asociaciones- son escuelas de democracia, como lo planteó Tocquellive (1989)

En ese sentido, al repasar la política exterior de la última parte de la administración Pastrana Arango, se advierten dos ejes: uno que intenta mantener el réspice polum y se centra en la lucha contra las drogas ${ }^{14}$, como lo reconoce Diego Cardona Cardona (2001) Entonces, la cooperación internacional recibida se dirige a las entidades gubernamentales que enfrentaban el problema. El otro, da un giro para "lograr el respaldo de la comunidad internacional al proceso de negociación, incluido el respaldo político, la cooperación financiera y la asistencia técnica" (Pastrana, s.f.). Continúa el tema de las drogas, pero también son prioritarias áreas como los derechos humanos y el medio ambiente. Ello con la "Diplomacia por la Paz", con la que el presidente Pastrana logra realizar tres mesas de donantes entre el 2000 y el 2001 en Madrid, Bogotá y Bruselas, e incrementar los recursos de cooperación de 100 millones de dólares anuales a 500 millones, en promedio (García, 2015) Fue así como el país llegó a ser el principal receptor de $\mathrm{Cl}$ en la región ${ }^{15}$. Luego, el contexto vuelve a cambiar: estalla el 9/11 y la agenda queda securitizada. Un giro de cambio de siglo.

No obstante, hay que hacer un poco de historia, para mirar atrás y tener presente que fue en 1995 cuando se creó el Programa de Desarrollo y Paz del Magdalena Medio, producto del acuerdo suscrito entre dos organizaciones de la sociedad civil: el Centro de Investigación y Educación Popular $(\mathrm{CINEP})^{16}$ y la Sociedad Económica de Amigos del País

\footnotetext{
${ }^{13}$ Tres suelen ser los argumentos para tal aseveración: la antigüedad, la tradición electoral y la estabilidad institucional (Ministerio de Industria y Comercio: Procolombia, 2013).

${ }^{14}$ Plan Colombia con el apoyo de Estados Unidos.

${ }^{15}$ Desde la Unión Europea se apoyan los Laboratorios de Paz, que se explican más adelante.

${ }^{16}$ Una Organización No Gubernamental, ONG, con amplia experiencia en la investigación del liderazgo social, económico, político y cultural.
} 
(SEAP), entidad creada por el Partido Liberal Colombiano. En la movilización de la alianza inicialmente- jugaron un papel fundamental Ecopetrol y la Diócesis de Barrancabermeja, de la iglesia católica. Los no novatos en $\mathrm{Cl}$ saben del gran apoyo que estos programas han recibido de la Unión Europea (Jordan, 2017) Y ello porque se partió de una metodología participativa que posibilitaba el desarrollo de la red de ciudadanos, para construir capital social técnicamente capacitado para elaborar y poner en marcha proyectos priorizados por ellos mismos. Así que los recursos de cooperación han seguido fortaleciendo a las organizaciones de la sociedad civil desde la base, la construcción de paz y, por supuesto, el desarroIlo. Los Laboratorios de $\mathrm{Paz}$, han contado con un gran respaldo de la $\mathrm{Cl}$ europea.

Luego, vinieron las dos administraciones de Álvaro Uribe Vélez, que si bien, en el periodo 2002-2006, contó con una política exterior que tenía tres principios rectores ${ }^{17}$ y, dentro de sus líneas temáticas, se hacía referencia a cooperación internacional y relaciones con la sociedad civil, representó un profundo distanciamiento en términos de facilitar la participación para las organizaciones de la sociedad civil, en la vida política del país. Muy por el contrario, el acompañamiento de la $\mathrm{Cl}$ posibilitó el efecto bumerang ${ }^{18}$ de la sociedad internacional, especialmente de la europea, para presionar por un trabajo en democracia y en construcción de paz en el país. De ahí, el respaldo que tuvo la Alianza de Organizaciones Sociales y Afines para la Paz y la Democracia en Colombia ${ }^{19}$. La cooperación entre OSC no se hizo esperar, por ejemplo, Human Rights Watch alertó al mundo sobre el incumplimiento de las recomendaciones de derechos humanos realizadas por la ONU e instó a monitorear la situación en Colombia. Lo propio hizo Amnistía Internacional, el entonces portavoz del comisario europeo de Asuntos Exteriores y, el Departamento de Estado de los Estados Unidos ${ }^{20}$. No es solo el discurso, pues este va acompañado de recursos de $\mathrm{Cl}$ para adelantar el monitoreo. Durante el segundo periodo administrativo, la actitud fue la misma, y la $\mathrm{Cl}$ se dirigió a las organizaciones sociales especializadas y los grupos de base. Basta nombrar la Coordinación Colombia, Europa, Estados Unidos ${ }^{21}$, que es una de las plataformas asociadas a la Oficina Internacional de Derechos Humanos- Acción Colombia $(\mathrm{OIDHAC})^{22}$, pero se puede nombrar una lista extensa por las dinámicas que este agente social, político y de desarrollo ha tomado en las relaciones internacionales.

\footnotetext{
${ }^{17}$ Eran: gobernabilidad democrática, responsabilidad compartida y solidaridad (Ministerio de Relaciones Exteriores, 2003).

${ }^{18}$ Ampliar en Keck y Sikkink (Keck \& Sikkink, 2000: 32).

${ }^{19}$ Concentra 10 sectores importantes del país (sectores sociales y organizaciones especializadas) que están presentes en todas las regiones y cuenta con el respaldo de 125 organizaciones. Se constituyó a partir del documento "La solución pacífica y la democracia son el camino", presentado en la Conferencia de Londres en julio de 2003.

${ }^{20}$ Incluso llegó a ponerse en duda la continuidad del apoyo de Estados Unidos a Colombia (en materia militar) y con la Unión Europea las relaciones se enturbiaron (Carvajal \& Amaya, 2005: 37-39).

${ }^{21}$ Es una red de 233 organizaciones colombianas que trabajan en la promoción, divulgación y defensa de los derechos humanos. Es autónoma, amplia y plural que adelanta trabajo compartido entre organizaciones no gubernamentales y organizaciones sociales del país. Cuenta con el apoyo de organizaciones internacionales de derechos humanos, agencias internacionales de cooperación y grupos de solidaridad (Revista Global Hoy, s.f.).

${ }^{22}$ Se remonta a la HEKs Suiza con la idea de juntar esfuerzos de organizaciones europeas e iglesias protestantes y trabajar articuladamente por los derechos humanos en Colombia. Desde 2009 se ha consolidado como Asociación Sin Ánimo de Lucro, en Bélgica, y siguen operando.
} 
En el primer periodo de gobierno de Juan Manuel Santos, se trazó la "Estrategia Nacional de Cooperación 2012-2014" (ENCl), donde se reconocía como uno de los desafíos:

Diversificar las fuentes de cooperación. Actualmente, los principales donantes son Estados Unidos, la Unión Europea y España, que representan las dos terceras partes de la cooperación que ha recibido Colombia en la última década. Fuentes con que debemos seguir trabajando, pero al mismo tiempo tenemos el reto de conquistar y ampliar la cooperación de otros países en Europa - como Reino Unido y Alemania- y en Asia como China, Japón y Corea-, además de captar recursos de otras nuevas economías emergentes (Agencia Presidencial de Cooperación Internacional en Colombia, 2013)

Y dado que, desde 2010, Colombia fue categorizada como País de Renta Media Alta (PRMA) (Ministerio de Relaciones Exteriores, s.f.), se ha buscado entrar al club de los ricos: a la Organización para la Cooperación y el Desarrollo Económicos (OCDE) ${ }^{23}$. Bien, como PRM ha de ofrecer cooperación; entonces, la ENCl 2012-2014 planteó consolidar las fortalezas para intercambiar experiencias. Lo que se encuentra es que se oferta desde la institucionalidad, basta mirar el Área de Oferta de Cl de APC. Y se olvida de la oferta de valor de las OSC que, no solo han ganado por el fortalecimiento que han recibido de la $\mathrm{Cl}$ sino que cuentan con experiencia en territorio. Las OSC colombianas "son agentes que le posibilitan al país posicionarse de una nueva manera en la arena internacional" (Marín Aranguren, 2017, p. 260) En conversaciones con Andrés Uribe (2017), se advierte que en APC Colombia no se logra visibilizar ese potencial. También debe subrayarse que, en términos de demanda, se priorizan los recursos de la cooperación para apoyo de la institucionalidad, sea para los servidores públicos o en términos tecnológicos, "porque es el deber ser para la entidad" (Uribe, 2017) Desaparece la lógica de Tocqueville, en términos de fortalecer a la sociedad civil como escuela de la democracia, porque allí se aprender a participar. Se olvida una de las recomendaciones que ya había planteado la Universidad Externado de Colombia (Acción Social, s.f.) a la, entonces, Agencia Presidencial para la Acción Social y la Cooperación Internacional, en el sentido de no limitar la cooperación internacional a la ejecución de proyectos (Acción Social, s.f: 92) y, por el contrario a impulsar esas lecciones aprendidas.

Para el 2015-2018, en términos de cooperación, se definió una hoja de ruta ${ }^{24}$ para incrementar el beneficio que obtiene la sociedad colombiana de la cooperación. Obsérvese que aun con el compromiso de ofertar cooperación, se continúa dejando de lado el conocimiento adquirido por las OSC con la $\mathrm{Cl}$.

Ahora bien, en términos de montos de la $\mathrm{Cl}$, lo cierto es que las cifras se diluyen. En un análisis del comportamiento de la cooperación internacional no reembolsable en Colombia (CINR) (APC-Colombia, s.f.), la misma entidad reconoce que unos son los datos

\footnotetext{
${ }^{23} \mathrm{Al}$ cierre de la redacción de este artículo, Colombia entró en una revisión fuera de ciclo para que autoridades comerciales de Estados Unidos revisen en detalle el cumplimiento de las reglas de propiedad intelectual y derechos de autor. No obstante, el Presidente de la República, Juan Manuel Santos, consideró que "no hay razones para no aprobar el ingreso de Colombia a la Ocde" (Presidencia de la República, 2018). Lo cierto es que para la fecha de entrega definitiva de este artículo, Colombia (30 de mayo de 2018) había sido aceptada en el club de mejores prácticas.

${ }^{24}$ En ella se priorizan tres áreas temáticas: construcción de paz, desarrollo rural sostenible y conservación y sostenibilidad ambiental (APC-Colombia, s.f.)
} 
que se reportan al Ciclope ${ }^{25}$ y otros son los de la CAD de la OCDE. De manera puntual, se anota en el documento que: "mientras que, para la OCDE, los Estados Unidos aportan más de la mitad de los recursos de CINR, para APC Colombia su contribución alcanza un $25 \%$ de la cooperación" (APC-Colombia, s.f., p. 11)

Tomando la información de APC Colombia, en una primera mirada, se advierte que, en 2015, el 43\% de la CINR en Colombia se invirtió en la paz. Ello en razón al "compromiso de los cooperantes con el proceso de paz de La Habana" (APC-Colombia, s.f.:v 4), que hoy es un Acuerdo firmado y protocolizado en el Colón, pero que flaquea desde el fast track que se adelantó en el Congreso con los temas de la Justicia Especial para la Paz $(J E P)^{26}$ y en el periodo electoral colombiano ${ }^{27}$. Entonces, se confirma esa hipótesis de Javier Garay Vargas (2010, p. 154 y ss), cuando hace un par de años, anotaba que en Colombia la cooperación es clave en la política exterior más como reacción a su incapacidad para responder a las necesidades internas.

No obstante, Colombia se encuentra en situación tal que debe hacer una jugada de ajedrez. De un lado, está el contexto internacional de la crisis financiera ocasionada por el subprime o colapso de la burbuja inmobiliaria de Estados Unidos, que hace que la cooperación internacional gubernamental tienda a reducirse. Del otro lado, en el contexto interno están: el Acuerdo Final para la Terminación del Conflicto y la Construcción de una Paz Estable y Duradera y, las conversaciones con el ELN, que hacen que los cooperantes no se retiren abruptamente del país. No obstante, tienen eco los cuestionamientos que la comunidad internacional hace sobre el manejo técnico de los aportes (Caracol Radio, 2018)

Lo cierto es que, desde 2010, Colombia ha sido reconocida como un País de Renta Media (PRM), por eso -a la vista de muchos (Prado Lallande, 2015, p.104-105)- es insostenible mantener la colaboración a un PRM. Desde entonces, urge la necesidad de plantear una estrategia de salida y dejar de relacionar la cooperación con el logro de los objetivos de política exterior ${ }^{28}$ (Acción Social, p 92)

En realidad, como anotó el director de la Agencia Suiza para el desarrollo y la Cooperación, Fabrizio Poretti (2017):

No tiene presentación que nosotros, con nuestros impuestos, paguemos, porque en Colombia los ricos no pagan impuestos para acabar con la inequidad; pero, tampoco queremos dejar a las comunidades y volver en unos años para empezar a construir nuevamente. Hoy hay tejido social en el territorio y debe fortalecerse. También tiene que robustecerse la institucionalidad gubernamental. De ahí que trabajemos en los dos frentes: las entidades del Estado y las OSC.

De todas maneras, las agencias de cooperación se articulan con las realidades de los territorios. Por ejemplo, al inicio del periodo de la investigación se daba más ayuda

\footnotetext{
${ }^{25}$ Desde 2016, el Ciclope es el sistema de información de APC Colombia; antes se denominaba Sistema de Ayuda Oficial al Desarrollo (SIAOD).

${ }^{26}$ La Corte Constitucional le puso piso: serán 12 años en los que el Acuerdo Final no podrá modificarse.

${ }^{27}$ Más ahora, cuando se sindica a un ex comandante guerrillero de las FARC de cometer delitos relacionados con el narcotráfico, luego de la firma del Acuerdo Final y de cuestionarse si ha de ser extraditado o no.

${ }^{28}$ En la investigación adelantada por el CIPE de la Universidad Externado de Colombia, se entrega una lista de 50 recomendaciones.
} 
humanitaria, hoy hay más cooperación al desarrollo. Primero se hacía a través de organismos multilaterales (Organización de las Naciones Unidas, Comité Internacional de la Cruz Roja, etc. Ahora, la cooperación es directa, y también hay plataformas. Unos y otras se articulan con organizaciones locales y -también- con la institucionalidad. Poretti (2017) sostiene que crean mecanismos de autoprotección y fortalecimiento. Entonces, el conocimiento del terreno les permite no solo desarrollar estrategias con el concurso de unos y otros, sino trasladar mensajes importantes a través de policy dialogue o incidencia política, escalando problemas para encontrar soluciones.

Sean donantes/cooperantes o socios/receptores de la ayuda, han de comprometerse con los principios y compromisos de la Declaración de París ${ }^{29}$, del 2005, para mejorar la eficacia de la ayuda. En ese mismo orden de ideas, con las comunidades se trabaja para fortalecer capacidades (de formulación de proyectos, de gestión, metodologías para ser más eficientes, de organización, de liderazgo, para crear vínculos con la institucionalidad), y ello los habilita para ser más participativos, para hacer control social, para lograr el cambio que requieren en sus localidades. En la agencia, dice Poretti (2017), "le pedimos a las ONG suizas, que en sus proyectos siempre tengan un rubro de capacitaciones a ONG locales, porque siempre exigimos que trabajen con pares en el territorio, y que se haga énfasis en las personas"

La UE, por su parte, mantiene diálogo regular con diversas plataformas para crear confianza y consenso para la toma de decisiones: es el diálogo estructurado ${ }^{30}$, que se inscribe en el marco de lo que ya se conoce como la nueva arquitectura de la cooperación. En la hoja de ruta 2014-2015 (Unión Europea, s.f.), las mismas OSC reconocen que no hay procesos para la sistematización y escalonamiento de las innovaciones sociales ${ }^{31}$, se requieren más encuentros para el diálogo de saberes que permita intercambio de experiencias, se requieren recursos para fortalecer capacidades de las OSC y, se requiere fortalecer procesos de socialización de los resultados del trabajo de las OSC.

Aun con limitantes, puede anotarse que la interacción de las OSC con el Estado ha sido más dinámica, en parte, porque resulta de la solicitud que la $\mathrm{Cl}$ hace a los Estados. No obstante, las convierte en competidoras por los recursos de la $\mathrm{Cl}$, y ello no solo genera malestar sino que en la dimensión de acceso a los recursos ${ }^{32}$, limita los entornos propicios para las organizaciones.

Aquí se ha hecho referencia a la cooperación internacional desde el socio/ receptor, desde Colombia; en cada una de las administraciones presidenciales que ocupan el

\footnotetext{
${ }^{29}$ Los principios son cinco (5): apropiación, alineación, armonización, gestión orientada a resultados y mutua responsabilidad. Ampliar en http://www.oecd.org/development/effectiveness/34580968.pdf

${ }^{30}$ Es informado entre las OSC, el Estado y la cooperación internacional en Colombia, de modo que los proyectos financiados con cooperación internacional europea cuenten con la participación de la mayor cantidad de actores posibles.

${ }^{31}$ Jordan (2017) recuerda que, tras identificar la necesidad, se dieron a la tarea de apoyar un ejercicio que fuera alternativamente innovador: el armadillo, fue el beneficiario de esos recursos de cooperación con los que se logró organizar y capitalizar el saber hacer de 26 programas de desarrollo y paz. Una iniciativa de la Redprodepaz, que creó la primera biblioteca virtual especializada en la construcción de paz en Colombia.

${ }^{32}$ Las dimensiones obligatorias del entorno propicio tiene que ver con: garantía al derecho de asociarse, garantía al derecho y las libertades de las ESAL, acceso a los recursos, derecho a la libertad de expresión, derecho a la reunión pacifica, rol político de la ESAL, sistema impositivo y derecho a la información pública.
} 
periodo de la investigación. Luego se hizo referencia a un par de agencias, para tener la perspectiva del otro lado. No podía faltar la mirada de algunas OSC nacionales: se toma el caso de "Fundación Paz y Reconciliación", "Cinep", y la "Corporación Nuevo Arco Iris". No son las únicas, pero pueden pungir como referentes, sea por la cantidad de recursos que manejan; la historia y el nivel especializado que logran desarrollar; y la sostenibilidad que han logrado.

En el caso de la Fundación Paz y Reconciliación ${ }^{33}$, que es quizá la más nueva, vale anotar que nace de generar conocimiento y análisis cualificado en temas de seguridad. $\mathrm{La} \mathrm{Cl}$ ha sido, al decir del coordinador de la línea de democracia y gobernabilidad, "un elemento fundamental para garantizar los derechos y para promover las iniciativas desde la sociedad civil" (Montoya , 2017) Sin embargo, puede haber lecturas contradictorias en los territorios. De un lado, la $\mathrm{Cl}$ se convierte en un mecanismo de protección para los trabajadores, las ideas y los temas que abordan, porque se considera que aseguran transparencia. De otro, por contar con recursos de cooperación para realizar su labor, son señalados como intrusos que inclinan la balanza en la construcción de agendas públicas.

En ocasiones: "la $\mathrm{Cl}$ es el motor que impulsa iniciativas tanto en el territorio e incluso en el ámbito nacional, que ningún otro agente se atreve, como lo hizo de 2002 a 2010, cuando en el país se negaba el conflicto interno" (Montoya , 2017) Lo cierto es que, las OSC de segundo nivel e incluso las organizaciones de base, se fortalecen trabajando en red con las organizaciones de tercer y cuarto nivel. Al estar interconectadas, hacer veeduría, control social y participar en la vida política del territorio, se pueden desarrollar sinergias para que, no solo tengan recursos, sino que cuenten con entornos habilitantes.

En la Fundación Paz y Reconciliación cuentan con recursos de cooperación de USAID, UE, la cooperación noruega y otras agencias que tienen programas de fortalecimiento a la democracia. "Ellos son muy rigurosos: los proyectos deben estar bien escritos, el marco lógico debe ser preciso, las cuentas han de ser transparentes en lo financiero y en lo administrativo, los informes tienen que ser en las fechas programadas, pero hay total independencia en las metodologías. La manera de manejar la información depende exclusivamente de las políticas de Paz y Reconciliación" (Montoya, 2017)

Otra de las organizaciones de la sociedad civil a las que se quiere hacer referencia es un centro de pensamiento, investigación y acción social: la Corporación Nuevo Arco Iris. En poco más de 20 años de existencia, luego de un acuerdo de paz entre la Corriente de Renovación Socialista (desprendimiento del grupo guerrillero Ejército de Liberación Nacional-ELN) y el Gobierno, esta organización que hoy juega su papel de agente de paz y desarrollo ha contado con el apoyo de la cooperación internacional, para "al emprender actividades de investigación, capacitación, asesoría, comunicaciones y promoción social para contribuir en la superación del conflicto armado, la profundización de la democracia participativa, la dignificación de las víctimas, el fortalecimiento de proyectos sociopolíticos democráticos y de agendas alternativas de desarrollo nacional y territorial incluyentes" (CNAl, s.f.)

Se dice que, desde la reincorporación a la vida civil, el entonces embajador de los Estados Unidos, William Brownfield, les apoyó y luego la cooperación internacional desde; la Unión Europea; Embajadas de, Suecia, Noruega, España, Reino Unido, Reino de los Países Bajos, Canadá, Suiza y Holanda; Agencia Española para la Cooperación Internacio-

\footnotetext{
${ }^{33}$ Se crea en 2013
} 
nal (AECID), Fondo para la sociedad civil colombiana por la paz, los derechos humanos y la democracia (FOS- Colombia); Ford Foundation; Open Society Institute (OSI); Agencia Sueca para el Desarrollo Internacional (ASDI); Consejo Noruego de Refugiados (NRC); Programa de las Naciones Unidas para el Desarrollo (PNUD); United States Agency for International Development (USAID); Associates in Rural Development (ARD); Chemonics; United States Institute of Peace (USIP); Ayuntamiento de Barcelona; Fundación Avina; National Democratic Institute (NDI); Banco Interamericano de Desarrollo (BID); Catholic Organisation for Relief and Development Aid (Cordaid) y Mercy Corps.

Como se anotó, la lista puede ser larga, pero no se trata de listarlas ni de inventariarlas. Más bien, el intento es de evidenciar su fortalecimiento para la participación política, en el sentido planteado por Pasquino, a partir de la cooperación internacional.

\section{Ahora y futuro, a modo de consideraciones finales}

Los hallazgos que se quieren resaltar en este artículo, sobre la investigación adelantada en lo corrido del presente siglo hasta el 15 de junio de 2017, tienen que ver con el reconocimiento histórico al rol de los agentes que están involucrados con la $\mathrm{Cl}$ que recibe Colombia. Tanto los agentes estatales en sus diferentes niveles (destacando que cada vez hay más autoridades locales que se internacionalizan y así buscan cooperación internacional), como agentes privados (empresas y Entidades Sin Ánimo de Lucro) que no solo quieren operar recursos sino que ya están ofreciendo proyectos y servicios a sus pares en el mundo.

De un lado, se reconoce que la delimitación temporal posibilita una investigación mediante metodología de estudio de caso más precisa. No obstante, la coincidencia en la visión y percepción de donantes y socios muestra una realidad del interés en la formación de capital humano e institucionalidad pública y civil para la construcción de la democracia en el territorio colombiano. De otro lado, la persistencia en el robustecimiento de las OSC colombianas ha posibilitado que ellas generen su propia oferta de valor, pero ni políticos, ni académicos, ni la misma sociedad la conoce. Quizá por ello esa oferta de valor o ese saber hacer de las OSC no se convierte en referente cuando se oferta la cooperación del país.

La investigación, si bien focaliza los estudios de caso para encontrar evidencia empírica, también permite advertir las limitaciones en estudios sistemáticos que vayan a terreno. No obstante, las OSC colombianas tienen investigación, desarrollo e innovación

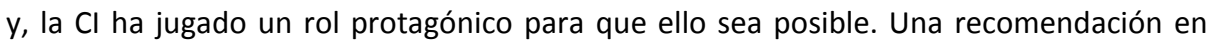
este sentido, sería sistematizar estos desarrollos para ofertarlos ahora que el país debe concursar en la arena internacional como PMR. Por ahora, siendo el tercer país latinoamericano que ingresa a la OCDE, tiene como "tarea" graduarse alcanzando el mínimo en términos de PIB, y una vez lo logre ${ }^{34}$, se le exigirá ofrecer cooperación en stricto sensu. Una labor de sistematización ha de ser de toda la nación, en especial del sector académico que le dé mayores elementos al Estado y a las mismas organizaciones de su oferta de valor, de su peso específico, de las mejores prácticas con las que se puede insertar en el mundo.

\footnotetext{
${ }^{34}$ Se espera que se alcance en 2031.
} 
Una consideración que no puede quedarse simplemente escrita es el reconocimiento de que: el diálogo político, la incidencia política o el policy dialogue que se ejerce desde las agencias de cooperación internacional ha posibilitado un ambiente o entorno habilitante favorecedor para la existencia misma de las OSC y para el ejercicio de sus roles $^{35}$ en: protección de ciudadanos, monitoreo, incidencia en políticas y comunicación política, socialización, construcción de comunidad, intermediación y facilitación entre ciudadanos y los diferentes niveles del Estado e, incluso, prestación de servicios. Esto es determinante para la inclusión democrática y la participación en la gestión de la política pública. De hecho está en la Agenda 2030, a lo largo de los 17 Objetivos de Desarrollo Sostenible (ODS) y tiene mucha fuerza en el ODS 17 porque esa Alianza Mundial es la que potencia transformaciones sociales.

Ya los estudios de Thania Paffenholz han señalado que, para construir y consolidar la paz, los donantes juegan un rol importante para fortalecer las iniciativas de las OSC, como también otros actores internacionales. Nótese que el ODS 16 precisamente hace referencia a la paz, la justicia y las instituciones sólidas. Luego, la presión que se ejerza mediante el efecto bumerang puede asegurar ambientes habilitantes para la acción de las OSC. No se trata solo del acceso a los recursos, que es una dimensión para poder hablar de un entorno propicio. $\mathrm{La} \mathrm{Cl}$ es el punto de entrada para garantizar derechos y libertades (asociación, expresión, reunión pacífica, etc)

A partir de las entrevistas semiestructuradas con cuarto agencias de cooperación y cuatro nacionales, esta investigación encontró que la interacción de las OSC con el Estado ha sido más dinámica, aun cuando prevalecen limitantes. Esto podría explicarse, en parte, porque resulta de la solicitud que la $\mathrm{Cl}$ hace a los Estados. Entorno propicio que, en el caso Colombia, ha sido desarrollado en la norma, pero que muchas veces ni los mismos funcionarios conocen. Lo que hace que las organizaciones deban demandar accountability horizontal y se convierte en un desgaste más antes que en un fortalecimiento como era la idea inicial. La Delegación de la Unión Europea en Colombia, por ejemplo, insiste en que se reconozcan a las OSC como actoras claves del desarrollo y por ende trabaja para favorecer el entorno habilitante, procurar la incidencia de las OSC en las políticas públicas, más si se trata de alcanzar los ODS y el fortalecimiento mismo de las organizaciones (esto es trabajo en gobernanza, rendición de cuentas, gestión de conocimiento y generación de impactos).

Ahora bien, lo cierto es que, en el ámbito nacional, la $\mathrm{Cl}$ ha posibilitado "el acercamiento e involucramiento de la sociedad civil para lograr una participación efectiva en la discusión de los temas de la agenda de negociación y en la implementación de los acuerdos" (García, 2015) Sin embargo, la parte de la implementación es una tarea pendiente. Más cuando para la entrega de este artículo se discutía en el contexto nacional sobre la transparencia en el manejo de los cuatro fondos que se han creado para la implementación de los acuerdos finales.

En el ámbito internacional, la $\mathrm{Cl}$ ha posibilitado la participación de las OSC colombianas en escenarios como Río+20, que no se trabajó en el artículo, pero fueron los derivados de las discusiones post-2015 los que posibilitaron llegar a la Agenda 2030. No es un secreto el liderazgo de Colombia en la construcción de los ODS, donde la discusión Esta-

\footnotetext{
${ }^{35}$ En el marco teórico de democracia, desarrollo y construcción de paz, Thania Paffenholz (2009) destaca este abanico de roles que observan las OSC. No es sólo un papel y no son ni lineales ni estáticos.
} 
do-OSC fue amplia. Tampoco lo es el rol en el seguimiento a la implementación de los mismos. Colombia ha sido país piloto (2016 y 2018) al entregar informe de avance en la Asamblea General de la ONU, y las OSC colombianas han sido activas con los informes luz que se discuten previamente en Nueva York.

Si bien este es solo un primer acercamiento desde otra mirada, los primeros hallazgos permiten otras lecturas de lo que sucede con la $\mathrm{Cl}$ en el territorio. Pueden ser luces tenues, pero dejan ver transformaciones o cambios en la gente y en la apropiación de temas como la participación política, la incidencia que se logra en agendas, la ampliación de entornos habilitantes y la construcción de tejido social que se requiere para generar capital social.

Estos hallazgos son referentes para investigaciones más profundas en Colombia, pero también lo han de ser para otros países de la región que han recibido y siguen recibiendo recursos de $\mathrm{Cl}$. Más aún, pueden incentivar líneas de trabajo investigativo para los 12 años que aún se requieren de implementación de la Agenda 2030 que busca "no dejar a nadie atrás".

\section{Bibliografía:}

Acción Social. (s.f.). La cooperación internacional hacia los países de renta media: una aproximación al caso de América Latina y Colombia. Bogotá: Presidencia República de Colombia: Agencia Presidencial para la Acción Social y la Cooperación Internacional.

Acosta, M. (mayo-agosto de 2013). La emergencia de la sociedad civil como actor político de alcance mundial: amenazas y desafíos. Revista Mexicana de Política Exterior(98), 149-166.

Agencia Presidencial de Cooperación Internacional en Colombia. (2013). Estrategia Nacional de Cooperación Internacional 2012-2014. Bogotá: Inter-American Development Bank.

APC-Colombia. (s.f.). Análisis del comportamiento de la cooperación internacional no reembolsable hacia Colombia. Recuperado el 12 de junio de 2017, de APCColombia/ Publicaciones:

https://www.apccolombia.gov.co/sites/default/files/archivos_usuario/public aciones/analisis_del_comportamiento_de_la_cooperacion_internacional_no _reembolsable_hacia_colombia.pdf

Caracol Radio. (2 de abril de 2018). Colombia Sostenible responde a preguntas sobre recursos para posconflicto. Caracol Radio. Obtenido de http://caracol.com.co/radio/2018/04/03/nacional/1522712936_554366.htm I

Cardona, D. (2001). La política exterior de la Administración Patrana (1998-2002) Hacia una evaluación preliminar. Colombia Internaciona/(53), 53-74. Recuperado el 12 de junio de 2017, de http://revistas.uniandes.edu.co/doi/pdf/10.7440/colombiaint53.2001.03

Carvajal, L., \& Amaya, R. (mayo de 2005). La política Exterior de la Administración Uribe 
(2002-2004): Alineación y securitización. Cuadernos del Cipe, 69.

CCONG. (diciembre de 2014). Estudio Piloto sobre Entorno Propicio en Colombia. Obtenido de Confederación Colombiana de Organizaciones No Gubernamentales: http://ccong.org.co/files/480_at_Ambiente\%20propicio.pdf

CCONG. (2016). ¿Estamos listas para la agenda de desarrollo sostenible? Oferta de Valor de la ONG-OSC 2014-2015. Bogotá: Confederación Colombiana de ONG.

CNAI. (s.f.). Quiénes somos. Obtenido de Corporación Nuevo Arco Iris: http://www.arcoiris.com.co/\%C2\%BFquienes-somos/

Defensoría del Pueblo. (julio de 2018). Homicidios de líderes sociales y defensores DD.HH. Bogotá, Colombia.

Diez de Sollano, C. (Enero-abril de 2015). El diálogo con la sociedad civil: el reto de la articulación. Revista Mexicana de Política Exterior(103), 145-165.

Garay Vargas, J. (2010). ¿Política exterior o política de cooperación? Una aproximación constructivista al estudio de la política exterior colombiana". Bogotá: Universidad Externado de Colombia.

García, J. (2015). Cooperación internacional y posconflicto en Colombia: más allá de los recursos económicos. Sextante(5). Recuperado el 10 de julio de 2017, de https://sextante.uniandes.edu.co/index.php/ejemplares/sextante5/horizontes/cooperacion-internacional-y-posconflicto-en-colombia

Glennie, J., \& Alonso, J. A. (1 de junio de 2015). What is development cooperation? Four criteria to help define it. Recuperado el 12 de mayo de 2016, de Global Policy Journal: http://www.globalpolicyjournal.com/blog/01/06/2015/whatdevelopment-cooperation-four-criteria-help-define-it

Ianni, V. (2005). La coiedad civil y la cooperación internacional al desarrollo. Enfopques teóricos y modalidades de acción. Madrid, España: IEPALA Editorial.

Jordan, V. (03 de abril de 2017). Oficial de Cooperación en Delegación de la Unión Europea en Colombia. (E. Marín Aranguren, \& A. Sanabria, Entrevistadores)

Keck, M., \& Sikkink, K. (2000). Activistas sin fronteras. México, México: Siglo Veintiuno Editores.

Marín Aranguren, E. (2017). El 3.0 de las organizaciones de la sociedad civil colombianas robustece la cooperación sur sur. En E. Marín Aranguren, \& P. Ruiz Camacho, Cooperación y Academia: una relación pendiente en Colombia (págs. 217268). Bogotá, Colombia: Universidad Externado de Colombia.

Massal, J. (2007). Socioedad Civil Internacional ¿Un poder Global? Análisis Político, 20(61), 54-72.

Ministerio de Industria y Comercio: Procolombia. (18 de julio de 2013). Por qué se dice que Colombia tiene la democracia más antibua de América Latina. Obtenido de Marca Colombia: http://www.colombia.co/esta-es-colombia/historia/porque-se-dice-que-colombia-tiene-la-democracia-mas-antigua-de-americalatina/ 
Ministerio de Relaciones Exteriores. (2003). Política Exterior de Colombia. Gobernabilidad democrática, responsabilidad compartida y solidaridad. 2002-2008. Bogotá, Colombia: Imprenta Nacional de Colombia.

Ministerio de Relaciones Exteriores. (s.f.). Cooperación Internacional. Recuperado el 09 de junio de 2017, de Cancillería:

http://www.cancilleria.gov.co/international/politics/cooperation

Montoya , C. (30 de marzo de 2017). Coordinador de la Línea de Democracia y Gobernanza, de la Fundación Paz y Reconciliación. (A. Sanabria, Entrevistador)

NED y ICNL. (s.f.). Grupo de Trabajo de la Comunidad de Democracias. Recuperado el 2 de mayo de 2017, de Movimiento Mundial para la Democracia. La Defensa de la Sociedad Civil:

http://www.defendingcivilsociety.org/sp/index.php/working_group

North, D. (1993). Instituciones, cambio institucional y desempeño económico. México: Fondo de Cultura Económica.

Paffenholz, T. (2009). Civil Society and Peacebuilding. Ginebra: Centre on Conflict, Development and Peacebuilding.

Pasquino, G. (1993). Participación política, grupos y movimientos. En G. Pasquino, S. Bartolini, M. Cotta, L. Morlino, \& A. Panebianco, Manual de Ciencia Política (págs. 179-215). Madrid, España: Alianza Universidad Textos.

Pastrana, A. (s.f.). Diplomacia por la paz. Política exterior colombiana que busca la paz nacional e internacional. Recuperado el 11 de junio de 2017, de Biblioteca presidencial virtual Andrés Pastrana: http://andrespastrana.org/portfolioitems/la-diplomacia-por-la-paz-politica-exterior-colombiana-que-busca-lapaz-nacional-e-internacional/

PNUD. (s.f.). Organizaciones de la sociedad civil. Recuperado el 4 de julio de 2017, de Programa de las Naciones Unidas para el Desarrollo: http://www.undp.org/content/undp/es/home/ourwork/funding/partners/ci vil_society_organizations.html

Poretti, F. (14 de marzo de 2017). Director de Cooperación de la Agencia Suiza para el desarrollo y la Cooperación. (E. Marín Aranguren, \& A. Sanabria, Entrevistadores)

Prado Lallande, J. (2015). La cooperación internacional para el desarrollo. Acciones, desafíos, tendencias. Madrid, España: La Catarata: Instituto Universitario de Desarrollo y Cooperación.

Presidencia de la República. (22 de marzo de 2018). Noticias: Presidencia de la República de Colombia. Obtenido de No hay razones para no aprobar el ingreso de Colombia a la Ocde: http://es.presidencia.gov.co/noticia/180322-No-hayrazones-para-no-aprobar-el-ingreso-de-Colombia-a-la-Ocde-PresidenteSantos

Revista Global Hoy. (s.f.). Coordinación Colombia, Europa, Estados Unidos. Obtenido de Global: http://www.gloobal.net/iepala/gloobal/fichas/ficha.php?entidad=Agentes\&i 


\section{d=14995\&opcion=descripcion}

Tassara, C. (2016). Cooperación internacional para el desarrollo: gobierno, economía y sociedad. Evolución de las políticas y escerarios futuros. Bogotá: Universidad de La Salle.

Tocqueville, A. (1989). La democracia en América. Madrid: Aguilar.

Unión Europea. (s.f.). Colombia. Hoja de ruta de la UE para el compromiso con la sociedad civil en los países socios. Obtenido de European Union External Action: http://eeas.europa.eu/archives/delegations/colombia/documents/page_con tent/road-map-colombia_es.pdf

Uribe, A. (01 de febrero de 2017). Director de Gestión de Demanda. (E. Marín Aranguren, Entrevistador) 